\title{
ARTIGO
}

\section{CONSTITUIC̣ÃO E PRÁTICA DE PROFESSORES INOVADORES: UM ESTUDO DE CASO}

\author{
João Batista Siqueira Harres - (https://orcid.org/0000-0002-7089-5669) * \\ Pontifícia Universidade Católica do Rio Grande do Sul (PUC-RS), Porto Alegre - RS, Brasil \\ Valderez Marina do Rosário Lima - (https://orcid.org/0000-0002-2676-5840) * * \\ Pontifícia Universidade Católica do Rio Grande do Sul (PUC-RS), Porto Alegre - RS, Brasil \\ Gabriela Carolina Cattani Delord - (https://orcid.org/ 0000-0003-2283-5976) *** \\ Universidade de Sevilha, Espanha \\ Clara Inés Chaparro Susa - (https://orcid.org/0000-0003-1870-2943) **** \\ Universidade Pedagógica Nacional (UPN), Bogotá, Colômbia. \\ Rosa Inés Pedreros Martinez - (https://orcid.org/0000-0003-3120-0526) ***** \\ Universidade Pedagógica Nacional (UPN), Bogotá, Colômbia.
}

RESUMO: Como parte de uma pesquisa de âmbito internacional, com o fim de compreender processos de inovação educativa já consolidados em práticas de docentes, este trabalho analisa as vivências de um grupo de professores considerados inovadores. Coletaram-se narrativas de seis sujeitos que atuam ou que realizaram formação continuada na Escola Pedagógica Experimental (EPE) da cidade de Bogotá (Colômbia). Da Análise Textual Discursiva emergiram três categorias: história e trajetória profissional; concepções e prática docente; inovação permanente. Defende-se que a constituição de professores inovadores ocorre pela conjugação de fatores relativos aos contextos escolares e formativos, aliados a características intrínsecas aos sujeitos e que a sustentabilidade da inovação é garantida pela reflexão e transformação contínua da prática docente.

Palavras-chave: Inovação educativa; Escolas alternativas; Formação continuada.

\section{CONSTITUTION AND PRACTICE OF INNOVATIVE TEACHERS: A CASE STUDY}

ABSTRACT: As part of an international research that aims to understand some processes of innovative education, this research analyzes the experiences of a group of teachers considered innovators. We gathered narratives of six teachers that work or have performed in-service teacher education programs in EPE - Experimental Pedagogic School of Bogota (Colombia). The Discursive Textual Analysis method has generated three categories: history and professional path; teaching conceptions and practice; permanent innovation. It
* Doutor em Educação, Professor do Programa de Pós-graduação em Educação em Ciências e Matemática da PUCRS, Líder do Grupo de Pesquisa em Ensino de Física. Porto Alegre, RS - Brasil. E-mail:<joao.harres@pucrs.br >

** Doutora em Educação, Professora do Programa de Pós- graduação em Educação em Ciências e Matemática e de Educação da PUCRS, Porto Alegre, RS - Brasil.

E-mail:<valderez.lima@pucrs.br >

*** Doutora em Educação em Ciências e Matemática, Professora do Departamento de Didática das Ciências Experimentais e Sociais da Universidade de Sevilha, Espanha. E-mail:<gcattani1@us.es >

**** Mestre em Docêcia de Física, Professora da Faculdade de Ciências e Tecnologia da Universidade Pedagógica Nacional (UPN), Bogotá, Colômbia. E-mail:<chaparro@pedagogica.edu.co>

***** Doutora em Educação, Professora do Programa de Pós-graduação em Educação e do Programa de Educação em Ciências da Universidade Pedagógica Nacional (UPN), Bogotá, Colômbia E-mail:<rpedreros@pedagogica.edu.co> 
is argued that innovative teachers are formed with the help of a conjugation of factors related with scholar and formative contexts, allied to characteristics inherent to the subjects. The sustainability of innovation would be guaranteed by reflection and continuous transformation of the teaching practice.

Keywords: Innovative education; Alternative schools; In-service teacher education.

\section{CONSTITUCIÓN Y PRÁCTICA DE PROFESORES INNOVADORES: UN ESTUDIO DE CASO}

RESUMEN: Como parte de una investigación de ámbito internacional con el fin de comprender procesos de innovación educativa ya consolidados en prácticas docentes, este trabajo analiza las vivencias de un grupo de profesores considerados innovadores. Se recogen narrativas de seis sujetos que actúan o que realizaron formación continuada en la Escuela Pedagógica Experimental (EPE) de la ciudad de Bogotá (Colombia). Del Análisis Textual Discursivo surgieron tres categorías: historia y trayectoria profesional; concepciones y práctica docente; innovación permanente. Se defiende que la constitución de profesores innovadores ocurre por la conjugación de factores relativos a los contextos escolares y formativos, aliados a características intrínsecas a los sujetos y que la sostenibilidad de la innovación está garantizada por la reflexión y transformación continua de la práctica docente.

Palabras clave: Educación innovadora; Escuelas alternativas; Formación contínua. 


\section{INTRODUÇÃO}

Pesquisadores, gestores e muitos professores, além de outros agentes educativos, parecem estar em consenso com a necessidade de mudanças na educação. Apesar de haver desenvolvimento e aplicação de propostas de ensino com abordagens e metodologias inovadoras, autores como Menezes (2000) e Porlán et al. (2010) apontam que estes esforços ainda não foram suficientes para mudar a situação dominante de um ensino transmissivo e cujo resultado, em geral, fica aquém do desejável em termos de formação.

Pesquisas que analisam dificuldades e obstáculos, na tentativa de explicar as razões pelas quais esses esforços alcançam baixa repercussão, apontam, como responsáveis por boa parte desse fracasso, aspectos estruturais do trabalho docente e das escolas, somados a alterações superficiais que buscam resultados em curto prazo, além de propostas desconectadas do contexto escolar (FULLAN, 2001; CARBONELL, 2001; GARCIA, 2010).

Porém, essas mesmas pesquisas parecem centrar-se fortemente no mapeamento dos obstáculos que dificultam a implementação da inovação. Daí que, conhecida esta situação, julga-se pertinente analisar experiências bemsucedidas nessa direção. De fato, há poucas investigações na área que valorizam e divulgam experiências positivas. Conforme Miranda e Damico (2013), existe pouca informação a respeito do que pensam os professores que desenvolvem permanentemente atividades inovadoras. Na mesma linha, Roldão (2010) acredita que a dimensão das práticas e a dimensão teórica continuam sendo uma zona de tensão nas pesquisas em educação. Nesse sentido, Segura (2000) defende a ocorrência de mais pesquisas para a compreensão das mudanças efetivamente implementadas no ensino. Assim, este estudo, como parte de uma pesquisa de âmbito internacional sobre a sustentabilidade da inovação educativa ${ }^{1}$, teve por objetivo analisar as vivências de um grupo de professores considerados inovadores.

Os docentes que fizeram parte da investigação atuavam na Escola Pedagógica Experimental (EPE) da cidade de Bogotá (Colômbia) ou realizaram formação continuada nessa instituição. $\mathrm{O}$ artigo encontra-se organizado em cinco seções, além da Introdução. A primeira seção apresenta uma reflexão sobre o conceito de inovação e a segunda expõe o contexto da EPE. Na terceira, explicitam-se elementos do desenho metodológico. $\mathrm{Na}$ quarta, apresenta-se a análise das categorias emergentes: história e trajetória profissional; concepções e prática docente; inovação permanente. $\mathrm{Na}$ última seção, apresenta-se algumas implicações para a formação de professores inovadores.

\section{INOVACุ̃̃O E AC̣ÃO DOCENTE}

Inovação, na contemporaneidade, é um traço comum aos discursos que circulam em distintas esferas da sociedade. O recorrente uso do termo é justificado pela profunda transformação ocorrida nas últimas décadas nas formas de produção e distribuição de conhecimentos, em decorrência do desenvolvimento das tecnologias da informação e comunicação. Dito de outro modo, o mundo mudou e as mudanças imprimiram uma distância entre as atuais demandas da 
sociedade e a capacidade de seus integrantes atendê-las valendo-se dos expedientes que vinham sendo utilizados até então. Isso vem exigindo a idealização de outro modo de pensar e agir. Litto (1997) propõe a metáfora da "corredeira" para essa nova atuação, indicando uma preparação que possibilite aos sujeitos a tomada de decisões estratégicas enquanto desce, em um bote inflável, um rio caudaloso e cheio de pedras. É neste contexto que inovação torna-se palavra de ordem.

A inovação pode ser definida como a introdução de algo novo que provoque modificação na forma de realizar as atividades concernentes a determinados contextos. As mudanças, que caracterizam a inovação, são específicas para diferentes campos, tais como: tecnológico, social, organizacional, educacional, etc.

Particularizando para o campo da educação, o conceito de inovação é encontrado em Saviani (1989, p.23 e 24). O autor afirma inicialmente que "inovador é o que se opõe ao tradicional" e complementa dizendo que nem toda a mudança expressa uma inovação, pois para haver inovação faz-se necessária a ocorrência de reformulação "na própria finalidade da educação, colocando-a a serviço das forças emergentes da sociedade". Para o autor, a verdadeira inovação modifica a essência do projeto educativo, embora muitas vezes ocorram mudanças sobre elementos não centrais como, por exemplo, mudanças nos métodos de ensino, que promovem modificações, mas deixam inalterados os objetivos da educação. Carbonell (2001, p.19) reforça essa concepção ao afirmar que "as diferenças entre inovação e reforma têm a ver com a magnitude da mudança que se quer empreender".

Nessa linha de raciocínio, a fim de inovar em educação é necessário um desenho distinto do convencional para a formação de crianças e jovens. É preciso uma formação centrada no desenvolvimento de capacidades que auxiliem na tomada de decisões mais adequadas, qualificando a vida em nível individual e coletivo.

A vinculação entre inovar e ensinar ciências encontra-se presente em alguns estudos da área sendo possível destacar as pesquisas implementadas em programas de formação de professores. Nesta perspectiva, o ensino baseado em pesquisa (CRAWFORD, 2000) e a constituição de comunidades de prática (BALZANO, 2014) vêm sendo consideradas por muitos autores como estratégias importantes para o desenvolvimento profissional e, como consequência, para a implementação de uma educação inovadora. Confirmando essa tendência nas pesquisas, Minner, Levy e Century (2010), fazendo uma síntese de revisões anteriores e ampliando o total de estudos analisados (chegando a quase 140), observam que, no geral, estratégias de cunho investigativo promovem maior aprendizagem que as estratégias passivas.

Dentre estes estudos cita-se, também, Herrington et al. (2016) que investigaram, com professores, mudanças em crenças, atitudes e valores sobre ensino de ciências. Como resultado, os docentes implementaram propostas inovadoras de cunho investigativo em sala de aula após terem vivenciado experiências de pesquisa. Relatam os autores que as mudanças alcançadas, conceitualizadas a partir de um "espectro de crenças", foram além de transformações da própria prática, estendendo-se para toda a escola e, ainda, fatores pessoais e de contexto ajudaram nessas mudanças.

Na mesma linha, Shaharabani e Tal (2017), investigando o desenvolvimento profissional em longo prazo de quatro professores israelenses concluem pela importância de adaptar a inovação ao contexto de atuação dos sujeitos em formação para que as mudanças se sustentem ao longo do tempo. 
Além da formação de professores, outras pesquisas relatam resultados de experiências consideradas inovadoras aplicadas ao currículo de Educação Básica como é o caso de Barcellos e Guerra (2015) que discutem proposta inovadora para o ensino da física moderna. Diniz, Oliveira e Schall (2010), relatam estudo sobre livro didático sobre saúde, voltado a estudantes da Educação Básica, e considerado como proposta inovadora na década de 1980, enquanto Damrauf e Menegaz (2013) assumem como inovador um currículo de ciências intercultural. Ainda, outras pesquisas procuram compreender o significado de inovação em sua relação com as tecnologias digitais. Amorim (1998) entrevista docentes para conhecer suas percepções sobre inovação e tecnologia e López e Morcillo (2007) estudam os aportes das tecnologias digitais para o ensino de ciências na escola.

Nos estudos, recém-mencionados, utilizados como exemplo, a figura do professor é central, seja na explicitação de suas percepções, seja por experienciar - e avaliar - práticas consideradas inovadoras. Essa reflexão dá origem ao seguinte problema de pesquisa: Quais são os atributos apresentados pelos sujeitos da EPE, considerados professores inovadores? Essa é a pergunta que se pretende responder ao longo do artigo. Para avançar é importante conhecer melhor o contexto no qual o estudo foi realizado.

\section{INOVAÇÃO NA EPE E EM FOMENTO}

A EPE, fundada em 1977 na forma de uma cooperativa, é administrada por um grupo de professores que mantém a escola e um espaço de formação docente que, entre outras atividades, promove cursos de formação, apoia coletivos de professores para desenvolverem atividades inovadoras, desenvolve materiais e presta assessoria. Essa escola e o espaço de produção e reflexão coletiva vinculado à EPE, denominado Fomento, constituem o contexto de nossas reflexões.

Em relação à produção acadêmica da EPE, destacam-se, entre vários livros publicados, a construção teórica consolidada da experiência com as, assim chamadas, Actividades Totalidad Abiertas (ATAs) (SEGURA, 2000; SEGURA et al., 2000) e, mais recentemente nesse contexto das ATAS, a produção própria de peças para o desenvolvimento de projetos de robótica ${ }^{2}$. Segundo esses documentos e materiais, as ATAS geram a tensão cognitiva necessária para que, ao longo do desenvolvimento das atividades na escola, sejam enfatizadas as perguntas e os interesses dos estudantes.

Entre as atividades formativas da cooperativa EPE, está Fomento. Esse é um espaço de colaboração que propicia, em encontros sistemáticos, estudos, reflexão sobre a própria prática, leituras, discussão de autores e teorias. Os professores, nesse espaço, compartilham dificuldades e soluções para problemáticas comuns, interagem e se autocriticam.

Nesse espaço, formam-se coletivos, grupos de professores que inovam e investigam conjuntamente. Em geral, os grupos compartilham um projeto comum sobre o qual investigam e escrevem. Porém, cada um tem liberdade para desenvolver o tema em aula da maneira que lhe pareça mais prática e mais adequado. Os grupos se alteram praticamente a cada ano. Os temas de trabalho desses grupos, em geral, são interdisciplinares, abordando assuntos tais como sistemas autorregulados ou 
ambiente de aprendizagem. Via Fomento há também a possibilidade de interação com outros coletivos semelhantes. Isso permite vislumbrar novas temáticas e novas maneiras de trabalhar. Por fim, Fomento oferece um espaço de intercâmbio, muitas vezes não disponível na escola, para integração de professores inovadores.

\section{MÉTODO}

Esta investigação, de cunho qualitativo (DENZIN, 1989; DENZIN e LINCOLN, 2006; TRIVIÑOS, 1987; FLICK, 2009; STAKE, 2011), caracteriza-se pela abordagem naturalístico-construtiva (GUBA; LINCOLN, 1994), por prever chegar à compreensão do fenômeno investigado examinando-o no contexto em que ocorre e tomando por referência os entendimentos dos participantes sobre o tema estudado. Trata-se, ainda, de uma pesquisa do tipo estudo de caso (BOGDAN; BIKLEN, 1994; YIN, 2005), por analisar em profundidade uma experiência específica, o que, nesta pesquisa, significou entrevistar e analisar os depoimentos de professores que se envolveram de forma intensa com a EPE e que, ao longo de suas carreiras, vêm desenvolvendo práticas que podem ser consideradas inovadoras.

Os sujeitos da pesquisa - seis professores colombianos em exercício foram indicados pelos autores colombianos deste trabalho, tendo como critério a vasta experiência em processos de inovação. No ano da entrevista, 2014, dois sujeitos lecionavam na EPE (identificados doravante como P5 e P6) e quatro haviam tido vivências em projetos aplicados em outras escolas, mas produzidos no espaço de formação - Fomento - na cooperativa EPE (sujeitos P1, P2 e P4) ou na EPE (sujeito P3). O perfil do grupo é mostrado no Quadro 1 a seguir.

Quadro 1. Perfil dos sujeitos

\begin{tabular}{|c|c|c|c|c|c|c|}
\hline Sujeito & $\begin{array}{c}\text { Idade } \\
\text { (anos) }\end{array}$ & Sexo & $\begin{array}{c}\text { Área de } \\
\text { formação }\end{array}$ & $\begin{array}{c}\text { Nível mais alto } \\
\text { de formação }\end{array}$ & $\begin{array}{c}\text { Experiência } \\
\text { docente } \\
\text { (anos) }\end{array}$ & $\begin{array}{c}\text { Tipo de } \\
\text { escolals) }\end{array}$ \\
\hline P1 & 46 & Fem & $\begin{array}{c}\text { Tecnologia } \\
\text { (Design) }\end{array}$ & Especialização & 20 & Pública \\
\hline P2 & 49 & Fem & Biologia & Especialização & 11 & Pública \\
\hline P3 & 52 & Masc & Física & Especialização & 10 & EPE \\
\hline P4 & 56 & Masc & $\begin{array}{c}\text { Ensino de } \\
\text { Eletrônica }\end{array}$ & Mestrado & 29 & Pública \\
\hline P5 & 42 & Fem & Química & Especialização & 19 & EPE \\
\hline P6 & 37 & Fem & Biologia & Graduação & 12 & EPE \\
\hline
\end{tabular}

A coleta de dados ocorreu por meio de entrevistas individuais planejadas por toda equipe e realizadas presencialmente por um membro da equipe brasileira (terceiro autor) e outro da equipe colombiana (quarto ou quinto autor). As 
entrevistas foram transcritas em espanhol pela equipe brasileira (primeiro e terceiro autores) e revisadas pelos parceiros colombianos. Em apêndice são apresentadas as questões que orientaram as entrevistas dos professores da EPE.

Após a transcrição, os depoimentos foram analisados por meio de Análise Textual Discursiva (MORAES; GALLIAZI, 2007), método de análise de dados qualitativos que resultam, ao final, em metatextos produzidos pelo investigador. O método efetiva-se, inicialmente, por meio da desconstrução do material, unitarização. Nessa fase, as informações das entrevistas são individualmente isoladas, constituindo as unidades de significado, havendo um esforço do pesquisador em relacionar as unidades de significado e os objetivos do estudo, num processo que visa à construção da validade interna do estudo.

Com as unidades fundamentais à disposição, inicia-se a segunda fase do processo analítico, a elaboração de um sistema de categorias, com a reunião das ideias - convergentes ou divergentes - que, de algum modo, esclarecem parte da questão inicialmente formulada. Conforme Moraes e Galiazzi (2007), esse é um dos momentos mais favoráveis para a emergência de novas compreensões do fenômeno em estudo.

Nesta pesquisa, os pesquisadores brasileiros, de forma individual, procederam à desconstrução dos textos, na língua original das entrevistas, e realizaram uma primeira organização de categorias. Em etapa posterior, além da discussão, houve comparação sistemática dos resultados parciais a fim de organizar o sistema final de categorias. Esse processo, que caracteriza a triangulação de investigadores (FLICK, 2009), ocorreu de forma coletiva entre os autores brasileiros desse trabalho com o intuito de incorporar as distintas percepções e reflexões sobre o fenômeno analisado. O processo de análise resultou na emergência de três categorias, discutidas na seção seguinte, cujo texto final foi discutido e validado por toda a equipe.

\section{RESULTADOS E DISCUSSÃO}

Nessa seção, apresentam-se resultados da análise das entrevistas realizadas com professores que possuem práticas docentes consideradas inovadoras. O processo analítico, que encaminhou a resposta à questão de pesquisa inicialmente formulada, efetivou-se pela emergência das três categorias expressas a seguir.

\section{Categoria 1 - História e trajetórias profissionais de professores inovadores}

Durante a leitura das entrevistas, afloraram com intensidade ideias que denotam a relação entre decisões tomadas pelos docentes ao longo das trajetórias profissionais e características individuais dos professores. Nóvoa (1995, p. 31), ao discorrer sobre a inseparabilidade das dimensões pessoal e profissional, afirma que "ser professor obriga a opções constantes que cruzam nossa maneira de ser com nossa maneira de ensinar e que desvendam em nossa maneira de ensinar, a nossa maneira de ser", e é neste sentido que a análise do material possibilita reconhecer as influências da dimensão pessoal, com suas especificidades, na constituição do professor inovador. 
O conteúdo das narrativas dos entrevistados permite compreender atitudes por eles tomadas ante a acontecimentos ocorridos em diferentes momentos de suas carreiras. Nesta categoria, aprofunda-se o exame sobre ações e deliberações efetuadas pelos professores ao longo do percurso profissional. Duas ideias, recorrentes nos relatos, sustentam a argumentação da influência de fatores internos nas decisões dos docentes. São elas: a existência de convites para participação em eventos de diversas naturezas e a atitude dos docentes diante de fatos e situações interessantes.

Para os sujeitos entrevistados, as condições para inovar estão relacionadas a convites que podem surgir em diferentes momentos da vida profissional e cujas modalidades variam desde a participação em eventos até a realização de cursos, estágios e acesso a grupos de pesquisa. Neste sentido, a professora P1 menciona ter recebido convite para participar de um evento no qual poderia "mostrar projetos que tivessem alguma inovação". Ela escolheu divulgar um projeto que vinha desenvolvendo na escola com alunos que apresentavam incapacidade cognitiva. Segundo essa professora, a atividade era "uma espécie de feira de ciências e os docentes apresentavam experiências inovadoras de diferentes escolas". A referida mostra, cuja intencionalidade era a divulgação de experiências inovadoras, propiciava a reunião de professores com expectativas diferenciadas em relação à prática profissional, sendo caracterizada como um encontro com oportunidades "para o estudo, a aprendizagem, a reflexão" (P1).

A professora P5 comenta que a reunião de dois acontecimentos, logo no início da carreira, foi determinante para sua atuação e para o delineamento que imprimiu a sua prática docente. O primeiro foi um convite, formulado por um colega antropólogo, para assistir a um ciclo de conferências denominado Galileu-Newton. A professora P5 menciona ter ficado entusiasmada com o evento e ter encontrado lá um professor da EPE que lhe disse: “[...] estamos procurando um professor para ministrar aulas de Biologia e Química na escola. Gostarias de desenvolver esta atividade?". Este foi o segundo acontecimento. Ela aceitou o convite e avança em sua narrativa informando que os desafios não pararam por aí. Ao iniciar as atividades docentes, P5, formada em Química, soube que deveria trabalhar com crianças com idade em torno de 10 anos. Segundo a professora, a primeira reação a este novo convite foi de surpresa e de susto: "Como? Eu não tenho ideia de como se ensina leitura e escrita a crianças! Era impensável, eu estava muito assustada". Entretanto, P5 não recuou diante da proposta e acabou por encontrar formas de realizar, com êxito, a tarefa em questão. Nessa altura da narrativa, a professora aponta a importância de estar engajada a grupos de trabalho como forma de se fortalecer. Segundo ela, isso é "fundamental porque sozinho não se faz nada (...). $\mathrm{Na}$ atividade coletiva estamos sempre escutando o outro".

As ponderações de P5 encontram ressonância em estudos contemporâneos sobre formação de professores, como os desenvolvidos por Zeichner (1993), Ludke, Moreira e Cunha (1999), Tardif (2005), Imbernón (2010), Liberali (2010), dentre outros. Para esses teóricos, a reflexão e a análise do professor sobre a própria prática é condicionante para possíveis mudanças. Eles ressaltam, também, a importância da reflexão coletiva para a modificação de concepções e práticas docentes. Os encontros entre professores a fim de refletir sobre a docência, 
além do contato com soluções diferentes para a resolução de problemas comuns ensejam, ainda, a produção conjunta de práticas novas, inovadoras.

Ainda nesta direção, P4, professor de física, conta que, inicialmente, direcionou a vida profissional para a área industrial, mas, em seguida, constatou que havia aspectos da atividade que não o satisfaziam plenamente. Acercou-se, na ocasião, da Universidade Pedagógica Nacional. Ele prossegue em seu relato: “[...] estando por lá conheci uma atividade que se chamava 'Encontro com o Futuro', da Universidade Nacional da Colômbia”. Segundo P4, além de garantir uma regularidade em encontros, por seu caráter anual, o evento possuía, ainda, "uma coisa maravilhosa que se distanciava da formação, digamos assim, tradicional. Lá nos propunham problemáticas concretas, que nos faziam pensar e teorizar". Foi participando desse evento que P4 teve a oportunidade de refletir sobre distintos modelos de docência e tomar decisões sobre o caminho que desejava seguir. Freire (1996, p. 39), ao discorrer sobre reflexão crítica sobre a prática, afirma: “[...] quanto mais me assumo como estou sendo e percebo as razões porque estou sendo assim, mais me torno capaz (...) de promover-me do estado de curiosidade ingênua para o de curiosidade epistemológica". Em outro ponto da narrativa, P4 complementa seu raciocínio dizendo: "[...] eu penso que em todos estes anos de reflexão, de escrita, de desenvolvimento de projetos e de olhar as experiências de outros companheiros, vamos transformando nossa prática, às vezes, sem consciência".

Assim, convites para participação em eventos, de distintas modalidades, apresentam-se como oportunidades para inovar prática pedagógica, pois tendem a proporcionar vivências em espaços diferenciados, nos quais é possível a revisão das próprias convicções e o contato com novas possibilidades de gestão do processo pedagógico. Professores, pois, necessitam de convites que lhes permitam conhecer ideias e grupos que trabalham em perspectivas distintas da tradicional, mas o potencial para mudança presente neste cenário precisa encontrar eco na disposição interna dos professores para refletirem e reconstruírem-se a partir dessas experiências. É sobre receptividade, abertura ao novo, que se discorre a seguir.

A narrativa dos professores apresenta elementos que permitem entender sentimentos e emoções que guiam sua atitude frente aos acontecimentos de suas histórias profissionais. Alguns entrevistados comentam que percepções se alteraram com a finalização dos cursos de graduação e o ingresso na profissão docente. Sobre o primeiro contato com escola e alunos. A professora P1 expressa que, à saída da universidade, os professores "encontram muitas dificuldades para enfrentar a realidade e percebem que as aprendizagens teóricas não ajudam muito a solucionar os problemas que se apresentam”. P5, por sua vez, relembra ter tido uma formação muito centrada em um paradigma cientificista. "Fiz o trabalho de conclusão numa perspectiva de investigação em biologia e química", e menciona que essa visão mostrou-se insuficiente para exercer a docência. Já P6, por iniciar a ministrar aulas na EPE, recém-egressa da universidade, se sentia despreparada porque "na universidade me ensinaram a dar aulas tradicionais, e eu não sabia o que fazer com os alunos".

Relatos dessa natureza não chegam exatamente a ser originais. No entanto, o que se constata é que o grupo de entrevistados não aquiesceu diante da incompletude da formação, talvez reconhecendo, como Freire (1996), que ensinar exige consciência do inacabamento. $\mathrm{O}$ autor, ao rememorar sua trajetória, afirma que: 
Como professor crítico, sou um "aventureiro" responsável, predisposto à mudança, à aceitação diferente. Nada do que experimentei em minha atividade docente deve necessariamente repetir-se. Repito, porém, como inevitável, a franquia de mim mesmo, radical, diante dos outros e do mundo. Minha franquia ante os outros e o mundo mesmo é a maneira radical como me experimento enquanto ser cultural, histórico, inacabado e consciente do inacabamento. (FREIRE, 1996, p. 28 e 29)

Assim, cada um a seu modo, tomou atitudes que geraram a superação. Para P1, a superação ocorreu pelo atendimento a convites que surgiram e nos quais vislumbrava que poderia aprender nas trocas de experiências. Segundo a professora, os eventos são momentos muitos valorizados porque "nos colégios, muitas vezes não há esses espaços. Então, esses espaços são importantes pela possibilidade de interagir com docentes de outras escolas. Conhecer. Aprender. Realizar autocrítica". Para P5, o diferencial foi aceitar o desafio, sendo professora de química, de ensinar leitura e escrita aos estudantes, experiência que proporcionou a ela a compreensão de que "aprender a ler e a escrever não são questões só de linguagem, são questões afetas a todas as áreas do conhecimento", ampliando, assim, seu entendimento acerca das funções que poderia desempenhar. Para P6, a atitude distintiva foi a decisão de continuar trabalhando na EPE. Depois de muita insegurança e dificuldades iniciais, ela afirma: "[...] comecei a conversar com os demais professores e com os estudantes e comecei a compreender a escola, porque tu não entendes a escola se não a vives".

Em diferentes momentos das narrativas, é possível perceber a presença de traços comuns aos professores entrevistados e que, de certa forma, explicam as decisões tomadas: "Sempre fiz muitas coisas que não se encontram dentro do estabelecido, do esperado" (P5); "Se não tivesse percorrido este caminho, certamente teria buscado outro, imagino. Creio que estaria buscando uma maneira de escutar e ser escutada" (P1); "Se eu não pudesse ser uma professora inovadora eu não seria mais professora" (P6); "Quando penso em minha formação, entendo que sempre é produtivo o envolvimento em projetos de investigação" (P4); "Primeiramente temos que abrir o horizonte. Não desejar ter todas as coisas resolvidas" (P3). Nóvoa (1995), ao se referir à construção da identidade profissional, aponta três elementos que sustentam esse processo:

Adesão, porque ser professor implica a adesão a princípios e valores [...] Ação, porque na escolha das melhores maneiras de agir jogam decisões de fórum profissional e de fórum pessoal. [...] e Autoconsciência, porque em última análise tudo se decide no processo de reflexão que o professor leva a cabo sua própria ação. É uma dimensão decisiva na medida em que a mudança e a inovação pedagógica são intimamente dependentes deste pensamento reflexivo. (NÓVOA, 1995, p.16)

Assim, na perspectiva da relação entre características pessoais e prática docente inovadora, o estudo permitiu identificar atributos que emergem no entrecruzamento das características pessoais e comportamento profissional. Cabe, neste momento, a seguinte questão: que concepções fundamentam a prática docente destes professores inovadores? 


\section{Categoria 2 - Concepções e prática docente}

$\mathrm{Na}$ Categoria 2, a análise das entrevistas dos professores investigados também revelou características comuns na condução das atividades em sala de aula, além de evidenciar similaridades nas concepções que subjazem estas práticas.

O professor P3 referenciou que, em suas aulas, são realizados trabalhos com projetos de investigação e, a partir disso, são promovidas "as socializações dos avanços, os alunos expõem as dificuldades, têm a oportunidade de perguntar a seus companheiros [sobre] como fariam tal coisa. Então, minhas aulas são um grande debate e uma grande socialização de projetos". Enquanto isso, P1 mencionou que parte de problemas reais muito contextualizados buscando soluções: "Tem que partir muito da prática e da realidade". Os alunos "se fazem perguntas que devem ser respondidas, buscando o porquê. Eles mesmos vão revisando o tema". $\mathrm{Na}$ mesma linha, P4 afirmou que o importante é como entendem os problemas da cotidianidade que estão investigando e como os solucionam. "Estão sempre solucionando problemas, construindo coisas, experimentando. E isso, fazem [em] coletivo". Estes problemas "os desequilibra e lhes leva a pensar, a buscar informação" (P4). Segundo esse professor, nada há estabelecido. Na medida em que as atividades se desenvolvem "vão surgindo as inquietações" (P4).

É possível dizer que o delineamento de práticas docentes nessa perspectiva apoia-se na concepção construtivista, na qual, segundo Coll (1996), aprendizagem é entendida como capacidade de construir uma representação pessoal sobre o objeto a ser conhecido. Freire (1996, p. 47), ao falar do papel do professor nesse processo, refere: “[...] ensinar não é transferir conhecimento, mas criar as possibilidades para sua própria produção ou construção”. Tal concepção pode ser percebida a seguir.

Tentamos fazer experiências diferentes das normais em sala de aula, nas quais os estudantes sejam atores do seu próprio aprendizado. Experiências onde as crianças sejam mais dinâmicas. (P1)

Então, através dos projetos, podemos nos aproximar dos alunos como um ser humano, [ele] não é um número e não só um nome. (...) É como esse pensamento de Freire, em que o professor é como se fosse um caixa automático, que simplesmente ele recebe e dá a nota aos estudantes, sim? A educação tem que ser mais social, mais humana, mais de interação. (P2)

Observa-se, entretanto, que a existência de formas comuns na condução das atividades em aula não torna as práticas docentes iguais e, tampouco, previsíveis, encadeadas em uma sequência lógica determinada ou buscando um objetivo final preestabelecido. Ao contrário, sua natureza é diferenciada, e tais práticas singularizamse, principalmente, pela constante reflexão e revisão por parte dos docentes sobre elas. Associada a esse processo, ocorre a sistematização das práticas por meio da produção escrita, favorecendo a socialização da inovação e a sua avaliação crítica para melhora futura. Como consequência, os professores implementam mudanças permanentemente, procurando desenvolver com os alunos atividades em sintonia 
com a perspectiva social mutante e desafiadora da realidade.

Como princípio mais estruturante dessa prática, destaca-se o entendimento do grupo de professores sobre a importância dos alunos estarem envolvidos com as atividades de aprendizagem. Segundo os entrevistados, a forma de conduzir as situações de ensino busca promover a autonomia do estudante, desafiando-o a criar e inovar. Consideram, ainda, que a percepção sobre seu próprio crescimento e a responsabilidade e o compromisso de socializar com os colegas suas conclusões são essenciais para a formação integral do aluno. Os depoimentos de P2 e P4 ilustram a intenção de colocar o aluno como protagonista do processo de aprendizagem.

Cada um tem interesses bem particulares. E como tal, então devemos nos aproximar da realidade da criança. Ver como ele conhece e como ele aprende. (P2)

Trabalhando desde uma perspectiva que estamos construindo em torno da ciência e tecnologia contemporânea, onde as características são: o protagonismo do aluno, o trabalho coletivo, a construção de explicações, a inovação e modificação, a criação. Ou seja, aos alunos são propostas atividades nas quais estão sendo desafiados continuamente e estão socializando seus avanços. (P4)

Ao mesmo tempo, as considerações de P3, a seguir, denotam a intenção de contribuir para o desenvolvimento amplo do estudante como sujeito social.

Sentia que ali estavam formando-se seres humanos distintos. Não só pessoas cheias de um conteúdo específico, mas também pessoas que se preocupavam pela sociedade e [pelo] ambiente e por fazer as coisas bem. Me recordo muito. Foi algo que gostei bastante. (P3)

Para Kamii (1992, p. 72), “a essência da autonomia é que as crianças se tornem capazes de tomar decisões por elas mesmas" e, no que diz respeito aos acontecimentos escolares, Aebli (1991) afirma que a aprendizagem autônoma, com vista ao desenvolvimento do pensamento independente, pressupõe a vivência de cinco momentos fundamentais: a necessidade de o aluno estabelecer contato com as ideias, compreender fenômenos, solucionar problemas, exercitar atividades e manter a motivação. Os professores entrevistados parecem compartilhar esse entendimento, pois para a consecução de seus objetivos adotam estratégias de partir de problemas reais, conectados aos interesses dos alunos, e trabalhar com perguntas elaboradas pelos próprios alunos. Conforme explica P1: "A ideia como tal é tentar que eles, observando o objeto se façam perguntas. Que não partam da teoria, mas sim da prática, daquilo que estão vendo". O raciocínio do professor é complementado por P6, que diz: "[...] se uma aluna pergunta se e por que está chovendo, isso já pode ser motivo para a realização de uma atividade ou um projeto". Os projetos, estratégia bastante utilizada pelos professores que fazem parte do estudo, envolvem temas variados como robótica, questões ambientais, energia renovável, desenvolvimento de animais, dentre outros.

Coerente com a visão de aula aberta, teorizada pela própria EPE (SEGURA et al., 2000), os docentes optam pela inexistência de roteiros nas aulas. Para eles, cada aula é singular e tem o seu desenvolvimento próprio, como refere 
P2 ao relatar uma aula em que, enquanto trabalhava o tema das espirais, uma aluna trouxe uma concha e, sem esperar, de dentro dela saiu um caracol. A partir daí a aula mudou totalmente.

Então todo mundo se assombrou e disse, 'aiiii, isto está vivo. Professora que é isso?' 'É um caracol. E de onde tiraram o caracol?' 'Do jardim.' 'Professora, e que comem os caracóis?' 'Então, pois temos que consultar para ver o que comem os caracóis. Mas, segundo eu sei eles são herbívoros.' 'Professora, e como se chama isso que sai deles aqui?' 'Isso são os olhos.' 'E o que tem aqui em frente também são olhos?' 'Venham, tocamos neles.' Então, ao tocá-los os caracóis escondiam seus tentáculos. (P2)

Depois do ocorrido relatado por P2, surgiu o interesse de trazer um agrônomo para explicar mais coisas sobre os caracóis. A partir daí, não foi mais possível seguir na direção inicial, isto é, do estudo geométrico das espirais.

Então começaram a intervir diferentes pessoas na aula. E já não era só o discurso da professora (...) e o que eles podiam encontrar na internet, mas o que eles começaram a perguntar aos pais. (P2)

Assim, P2 complementa sua fala informando a descoberta do grupo de que os caracóis são importantes, alguns para produzir cremes cicatrizantes e para evitar rugas e varizes. "Os alunos chegavam com este pull de informação à aula. Então me desviou totalmente a aula. Mas foi pelo interesse das crianças” (P2).

A coerência com a visão de aula aberta estende-se ainda à visão de aprendizagem processual (COLL, 1996), pois os encaminhamentos para abordar problematizações que surgem se encontram associados às capacidades dos alunos naquele momento e a elementos do contexto:

O trabalho em aula está muito relacionado com os problemas do cotidiano. Com as capacidades dos estudantes e com as possibilidades que o contexto propicia em função dos recursos. Então, as aulas já não são aulas discursivas. São aulas que propõem a busca de explicações sobre um fenômeno ou sobre a construção de um artefato. (P4)

Para os docentes, à medida que os estudantes atribuem significado à atividade, ocorre um envolvimento emocional com a tarefa. Conforme destaca P5: "Quando um professor é capaz de escutar perguntas dos alunos, pode fazer coisas belas, no sentido que pode (...) gerar muita afetividade com a atividade". Nessa configuração de aula, a comunicação é permanente, como indica P4 quando menciona que "ninguém fica calado", pois na busca de "soluções e explicações para suas perguntas, os estudantes dialogam entre si e com o professor" (P1). Em algumas ocasiões, os resultados das pesquisas também são apresentados aos colegas de outras séries e em eventos externos à escola. Nessas apresentações, os alunos são incentivados a mostrar o que aprenderam a partir das próprias compreensões. Na mesma direção, P3 menciona que as atividades efetuadas para compreender determinado fenômeno levam os alunos a aproximarem-se de conteúdos conceituais de forma natural. Dito de outro modo, os conceitos, 
leis, fenômenos importantes são apreendidos pelos alunos e eles densificam sua bagagem científica nessa caminhada.

Em consonância com a forma de ensinar e de aprender descritas acima, as avaliações solicitam que os alunos expressem, com suas palavras e a partir de seus apontamentos, o que entenderam sobre os conceitos e fenômenos estudados: "A avaliação é: 'aqui estão as perguntas, tomem seus apontamentos e, com suas palavras, expliquem isso"” (P4).

Para além das concepções, outro ponto que chama atenção nas narrativas é a relação entre tipo de prática docente realizada e características do professor. Segundo P1, o docente precisa "encontrar alguma maneira de tornar o conteúdo atrativo às crianças, motivador, que lhes chame a atenção, que eles gostem". O entrevistado P6 complementa a ideia afirmando que um modo de assegurar a motivação do grupo é estar permanentemente alerta para identificar como os estudantes estão percebendo o projeto e suas vinculações com o mundo:

Quando trabalhamos com projetos, temos que escutar os estudantes para saber como eles estão percebendo o projeto com o mundo e, a partir daí, construir o projeto. A educação é descontextualizada. Nos preocupamos com isso e buscamos algo que tenha que ver com o dia a dia deles, com o social, o político, com o econômico, com a ciência, com a nação. (P6)

Portanto, sensibilidade para escutar e para perceber interesses e necessidades dos estudantes é uma característica valorizada pelos docentes, e o comentário de P5 traduz tal valorização: “[...] quando [um docente] é capaz de escutar as perguntas dos estudantes, pode fazer coisas bonitas, [...] pode gerar muita afetividade".

Aliado à necessária sensibilidade, os entrevistados ainda destacam outra característica: a importância de o professor possuir visão interdisciplinar e cultura ampla, posto que essa visão ajuda a promover conexões entre áreas distintas auxiliando-o a orientar os estudantes em suas ações de aprendizagem.

Outro tópico associado a características pessoais e referido pelos entrevistados é a relação de confiança estabelecida entre o professor e seus alunos. Essencialmente, há muita confiança entre eles. Estes professores acreditam que os estudantes são capazes de aprender e aprendem quando querem, quando têm compromisso com a própria aprendizagem e não porque "têm que aprender as coisas de memória" (P6).

Entretanto, há desafios em ser inovador. Como não há um livro de texto ou conteúdos prefixados, o professor não sabe exatamente o que vai acontecer em cada aula. Essa condição, geradora de insegurança em um cenário tradicional, é entendida pelos professores como uma oportunidade de ampliar seus próprios horizontes: "Tu mesmo vai construindo e isso implica em ler mais, estudar todo tempo. Isso me encanta na EPE porque todo o tempo estou estudando, lendo, aprendendo" (P6).

Assim, evidencia-se que a proposição de trabalho desses professores é diferente, inovadora. Mas como os professores chegaram a ter essa condição, como mergulharam num processo permanente de mudanças? A compreensão sobre esse processo encontra-se descrita na categoria a seguir. 


\section{Categoria 3 - Inovação permanente}

A análise das narrativas mostra reflexão sobre o processo de mudança permanente no qual os professores se veem envolvidos. Para o professor P4, o desenvolvimento de um professorinovador requer continuidade, acompanhamento, reflexão, busca de informação e, sobretudo, diálogo com os colegas de modo a compartilhar experiências, problemas e estratégias implementadas: "Só nessa circunstância se constrói a possibilidade de que um professor comece a ser uma pessoa inovadora" (P4). Os sujeitos entrevistados salientam, também, que nem todos os docentes aprendem da mesma maneira e ao mesmo tempo. Comentam que alguns professores, embora vivenciando experiências de formação continuada favorecedoras de mudança, continuam tendo por objetivo que os alunos aprendam a repetir os conceitos apresentados por eles. Porém, quando perseveram e permanecem nos grupos, compreendem que este não é, efetivamente, o maior objetivo do professor e, a partir daí, começam a modificar suas práticas e a vislumbrar outros projetos.

Portanto, são os coletivos, e não a formação universitária tradicional, que mais contribuem para a formação do docente inovador, conforme referem os entrevistados: "Eu aprendi mais em Fomento do que na universidade" (P2); "Sem a experiência dos colegas, de Fomento e da rede, creio que [seria] mais um professor tradicional" (P6). Nessa perspectiva, Carbonell (2001), ao tratar do tema de inovação pedagógica, defende a formação colaborativa como maneira de mudar a escola. Segundo ele, a cultura colaborativa inicia-se na escola, mas deve avançar para a formação de "redes que se transformam em coletivos de renovação pedagógica que pensem e avancem em direção a uma escola diferente junto com outros movimentos sociais; a única maneira de mudar a escola" (CARBONELL, 2001, p.112).

Este espaço educativo possui as condições, a partir de oficinas, por exemplo, para "mover o chão onde se apoia algo que eles creem” (P5). Assim, se pode romper o "caminho que já tem armado" (P5), passando da certeza para o convívio com a incerteza. Sobre a continuidade do desenvolvimento profissional, esse mesmo professor afirma ainda que "isso não é uma coisa que se dê automaticamente, mas que é um processo" (P5). Para ele, depende da sua predisposição e de uma sensibilidade para "observar as realidades que vive a escola" (P5). Assim, a reconfiguração da prática docente não ocorre de modo improvisado, ela é feita mediante um processo trabalhoso, seguindo um caminho orientado, mas flexível, condição para ser inovador.

Analisando a narrativa do professor P3 - "para ser um professor inovador tem que ser assim um professor aventureiro, tem que ser alguém que quer fazer coisas" e "a escola me deu total liberdade para fazer inovação" -, observa-se que os professores inovadores aproveitam as oportunidades que o sistema oferece apresentando propostas, buscando o enriquecimento mútuo dos envolvidos. Há consciência de que a aprendizagem e a valorização profissional decorrem da permanente investigação. Assim, para formação de docentes inovadores é essencial que haja espaço para participar de projetos e enfrentar os desafios da prática.

Segundo P1, a aprendizagem é permanente. Reflete-se sobre a prática continuamente, atualizando-a, pois os trabalhos e as temáticas evoluem, mudam. 
Mudam também os interesses e pensamentos dos estudantes e para acompanhálos é preciso ler muito, inovar e buscar novas práticas. Este é um percurso que, de forma inerente ao sujeito ou provocada nele, "necessita apoio [já que] não ocorre de um dia para outro. Não é rápido e nem fácil. Tem que haver muita constância, paciência e, sobretudo, interesse e vontade" (P1). Mas é preciso aceitar que "às vezes ocorrem erros e desacertos que devem ser superados e, cada vez, tentar fazer melhor" (P1). Reflexão e perseverança estão no cerne desse depoimento e parecem ser qualidades que ajudam a construir a autonomia profissional, pois essa, segundo Freire (1996, p. 107), "vai se constituindo na experiência de inúmeras, de várias decisões que vão sendo tomadas".

$\mathrm{Na}$ percepção de $\mathrm{P} 3$, os professores inovadores experimentam e testam atividades e propostas em aula e centram a autoavaliação desta atitude inovadora na capacidade dos estudantes de serem autônomos nas atividades. Assim, ele rompe paradigmas principalmente quanto ao currículo e quanto às formas de interação. A satisfação que isso proporciona ao aluno o ajuda a construir uma boa autoimagem e uma alta autoestima.

Ainda, P5 pondera que os professores inovadores tendem a permanecer envolvidos em projetos investigativos, em redes e em grupos que propõem ações inovadoras. Eles têm uma capacidade de aprender com os alunos, colegas e pais todos os dias, construindo o novo de forma coletiva.

O professor P4 enfatiza que o processo de transformação da prática a partir da reflexão, sobre o desenvolvimento de projetos e sobre as experiências de colegas, inicialmente ocorre de forma pouco consciente: "[...] depois de ter escutado os colegas, você reconhece que, às vezes, comete os mesmos erros e não havia percebido" (P4). Esse acompanhamento e reflexão dão segurança para avançar e chegar a ser inovador e investigador. Mas isso só se consegue com continuidade, com busca de informação, de diálogo para intercâmbio de experiências e solução de problemas. Nesse sentido, ressaltando este estado de permanente busca da inovação, P6 defende que os projetos são a melhor oportunidade para inovar.

Incorporar a inovação à prática pedagógica, de forma perene, requer disposição do professor para o constante questionamento sobre as ações/ atividades ocorridas em aula. A reflexão permanente, ao mesmo tempo em que contribui para o rompimento com práticas desenvolvidas de forma mecânica e irrefletida, provoca a busca de ações alternativas, favorecedoras de aprendizagem de conteúdos de todas as naturezas. Um aspecto relevante neste percurso é a necessidade de a reflexão realizar-se em grupo de docentes, sujeitos que partilham os mesmos interesses e desafios. É daí que surgem as práticas originais e inovadoras.

\section{CONSIDERAÇ̃̃ES FINAIS}

A investigação realizada permitiu compreender as vivências de um grupo de professores considerados inovadores, objetivo central da pesquisa e, ainda, identificar atributos dos docentes inovadores entrevistados.

O professor inovador é um sujeito inquieto, curioso, que aceita desafios que o desacomodem. Ele é propositivo, cria situações de ensino, testa atividades e, ao aplicá-las, reflete sobre os resultados obtidos, num constante processo de 
autoavaliação. Predispõe-se, também, a se envolver em atividades que proporcionem o exame de suas ações como docente. Para ele, participar de eventos, apresentando suas experiências e permitindo a apreciação de sua prática é um fator de positividade, que tem por finalidade qualificar seu fazer docente. O professor inovador, ainda, tem disponibilidade para interagir com outros professores, compreendendo essas ocasiões como oportunidades para aprender. Considera que no coletivo ampliamse as possibilidades de conhecer outras experiências, escutar diferentes pontos de vista e dialogar em torno do tema comum, qual seja a permanente reinvenção das formas de atuação, sempre objetivando qualificar o processo de aprendizagem de seus alunos. Quanto à concepção de aprendizagem escolar, o professor inovador é construtivista. Ele valoriza situações reais para a aprendizagem dos conceitos científicos, enfatiza o protagonismo discente, incentiva os questionamentos e cria situações de investigação sobre temas relevantes para os alunos.

Diante do exposto, tal como identificou Johnson (2007), considera-se que a vivência dos professores entrevistados em experiências de formação continuada inovadoras repercute favoravelmente em suas práticas como docentes. Como decorrência do estudo, se propõe que escolas e instituições de ensino superior disponibilizem aos professores, diuturnamente, momentos nos quais, de modo coletivo, os docentes tenham a condição de investigar e refletir sobre o que fazem.

Indica-se, ainda, que essas atividades de formação continuada sejam orientadas por aspectos como: (i) problematização do modelo tradicional de ensino; (ii) autoavaliação da prática docente; (iii) desenvolvimento de propostas alternativas de ensino, com acompanhamento dos resultados; (iv) diálogo entre pares e com os alunos; e (v) fortalecimento da pesquisa como atitude cotidiana. Dessa forma, espera-se que programas de formação de professores, agentes de políticas públicas e mesmo escolas isoladamente ou em rede possam atender o que as pesquisas vêm apontando como aspectos relevantes nos quais as práticas docentes devem avançar.

Para fortalecer este argumento, decorrente da perspectiva ampla na qual os professores da EPE se constituem, menciona-se o estudo de Capps, Crawford e Constas (2012), que analisou trabalhos empíricos, publicados em revistas bem avaliadas nos sistemas internacionais de classificação da produção científica. Os pesquisadores identificaram quatro fatores críticos que potencializam um efetivo desenvolvimento profissional: (i) melhoria no conhecimento específico da área de atuação, nas concepções sobre a natureza do conhecimento científico e nas concepções sobre pesquisa; (ii) mudança nas concepções relativas à importância da pesquisa no ensino de ciências e no nível de confiança na sua implementaçao em sala de aula; (iii) evolução na prática docente de cunho investigativo ou na habilidade para usar a pesquisa em sala de aula a partir de coleta de dados e da reflexão sobre a própria prática e (iv) melhoria dos estudantes no seu conhecimento específico, nas suas concepções sobre a natureza do conhecimento e sobre o que é e como pesquisar. Os autores destacam que nenhum trabalho, dos dezessete analisados, apresentou resultados com respeito a todas essas quatro dimensões.

Por fim, considera-se que a presente investigação contribui para o conhecimento na área de ensino de ciências tendo em vista as peculiaridades do contexto analisado. A EPE é uma escola e, ao mesmo tempo, uma comunidade de investigação da própria prática e de autoformação de seus integrantes. Implementa 
a muito tempo novas abordagens de ensino e de aprendizagem, configurando-se, portanto, como um caso já consolidado. Tendo em vista a influência de fatores contextuais no desenvolvimento profissional de docentes (SANDHOLTZ; RINGSTAFF, 2016), entende-se que estudos de contextos assim específicos são potentes para a produção de conhecimento sobre professores de ciências e sobre práticas inovadoras. E, nesta medida, indica-se a realização de mais estudos em instituições com características semelhantes.

\section{REFERÊNCIAS}

AEBLI, H. Factores de la enseñanza que favorecen el aprendizaje autónomo. Madrid: Narcea, 1991.

AMORIM, A. C. R. Biologia, tecnologia e inovação no currículo do Ensino Médio. Investigações em Ensino de Ciências, v. 03, n. 01, p. 61-80, 1998.

BALZANO,E.;CUOMO,F.;MINICHINI,C.;SERPICO,M.Communities of practice and continuous teacher professional development. Findings from eight case studies. In: CONSTANTINOU,C. P.; HADJIGEORGIOU, N. P. (ed.). Proceedings of the ESERA 2013 conference: science education research for evidence-based teaching and coherence in learning. Atenas, 2014.

BARCELLOS, M. E.; GUERRA, A. Inovação curricular e física moderna. Da prescrição à prática. Ensaio - Pesquisa em Educação em Ciências, v. 17, n. 02, p. 328-349, 2015.

BOGDAN, R; BIKLEN, S. Investigação qualitativa em Educação: uma introdução à teoria e aos métodos. Portugal: Porto Editora, 1994.

CAPPS, D. K.; CRAWFORD, B. A.; CONSTAS, M. A. A review of empirical literature on inquiry professional development: alignment with best practices and a critique of the findings. Journal of Science Teacher Education, v. 23, n.03, p. 291-318, 2012.

CARBONELL, J. A aventura de inovar. Porto Alegre: Artmed, 2001.

COLL, C. Um marco de referência psicológico para a educação escolar: a concepção construtivista da aprendizagem e do ensino. In: COLL, C.; PALACIOS, J. \& A. MARCHESI (org.). Desenvolvimento psicológico e educação. Psicologia da educação. vol. 2. Porto Alegre: Artes Médicas, p. 389-404, 1996.

CRAWFORD, B. A. Embracing the essence of inquiry: new roles for science teachers. Journal of Research in Science Teaching, v. 37, n. 09, p. 916-937, 2000.

DUMRAUF, A.; MENEGAZ, A. La construcción de un currículo intercultural a partir del diálogo de saberes: descripción y análisis de una experiencia de formación docente continua. Revista Electrónica de Enseñanza de las Ciencias, v. 12, n. 01, p. 85-109, 2013.

DENZIN, N. K. The research act. Londres: SAGE, 1989.

DENZIN, N. K.; LINCOLN, Y. O planejamento da pesquisa qualitativa. Teorias e abordagens. Porto Alegre: Artmed, 2006.

DINIZ, M. C. P.; OLIVEIRA, T. C.; SCHALL, V. T. Saúde, como compreensão de vida: avaliação para inovação na educação em saúde para o Ensino Fundamental. Ensaio - Pesquisa em Educação em Ciências, v. 12, n. 01, p. 119-144, 2010.

FLICK, U. Introdução à pesquisa qualitativa. Porto Alegre: Artmed, 2009. 
Constituição e prática de professores inovadores: Um estudo de caso

FREIRE, P. Pedagogia da autonomia: saberes necessários à prática docente. Rio de Janeiro: Paz e Terra, 1996.

FULLAN, M. The new meaning of education change. Nova York: Teachers College Press, 2001.

GARCIA, P. S. Inovações e mudanças: por que elas não acontecem na escola? São Paulo: LCT, 2010.

GUBA, E.; LINCOLN, Y. Competing paradigms in qualitative research. The handbook of qualitative research. Tousand Oask: Sage Publication, 1994.

HERRINGTON, D. G.; BANCROFT, S. F.; EDWARDS, M. M.; SHAIRER, C. I want to be the inquiry guy! How research experiences for teachers change beliefs, attitudes, and values about teaching science as inquiry. Journal of Science Teacher Education, v. 27, n. 02, p. 183-204, 2016.

IMBERNÓN, F. Formação continuada de professores. Porto Alegre: Artmed, 2010.

JOHNSON, C. C. Whole-school collaborative sustained professional development and science teacher change: sings of progress. Journal of Science Teacher Education, v. 18, n. 04, p. 629-661, 2007.

KAMII, C. Aritmética: novas perspectivas. Implicações da teoria de Piaget. Campinas: Papirus, 1992.

LIBERALI, F. C. Formação crítica de educadores: questões fundamentais. Campinas: Pontes, 2010.

LITTO, F. Um modelo para prioridades educacionais numa sociedade da informação. Revista Pátio, n. 03 , p. $15-21,1997$.

LÓPEZ, M.; MORCILLO, J. G. Las TIC en la enseñanza de la Biología en la educación secundaria: los laboratorios virtuales. Revista Electrónica de Enseñanza de las Ciencias, v. 06, n. 03, p. 562-576, 2007.

LUDKE, M.; MOREIRA, A.; CUNHA, M. Repercussões de tendências internacionais sobre a formação de nossos professores. Educação \& Sociedade, n. 68, p. 278-298, 1999.

MENEZES, L. C. Projeto pedagógico: mudar o quê, mudar por quê? Revista de Educação e Informática, n. 14, p. 29-34, 2000.

MINNER, D.; LEVY, A.; CENTURY, J. Inquiry-based science instruction-What is it and does it matter? Results from a research synthesis years 1984 to 2002. Journal of Research in Science Teaching, n. 47, p. 474-496, 2010.

MIRANDA, R. J.; DAMICO, J. B. Science teacher's beliefs about the influence of their summer research experiences on the pedagogical practices. Journal of Science Teacher Education, v. 24, n. 08 , p. 1241-1261, 2003.

MORAES, R.; GALIAZZI, M. C. Análise textual discursiva. Ijuí: Unijuí, 2007.

NÓVOA, A. Vida de professores. Porto: Porto Editora, 1995.

PORLÁN, R.; DEL POZO, R.; RIVERO, A.; HARRES, J. B. S.; AZCÁRATE, P.; PIZZATO, M. El cambio del profesorado de ciencias I: marco teórico e formativo. Enseñanza de las Ciencias, v. 28 , n. 01 , p. $13-46,2010$.

ROLDÃO, M. C. A diferenciação curricular revisitada: conceito, discurso e práxis. Aveiro: Universidade de Aveiro, 2010.

SANDHOLTZ, J. H.; RINGSTAFF, C. The influence of contextual factors on the sustainability 
João Batista Siqueira Harres | Valderez Marina do Rosário Lima | Gabriela Carolina Cattani Delord | Clara Inés Chaparro Susa| Rosa Inés Pedreros Martinez

of professional development outcomes. Journal of Science Teacher Education, v. 27, n. 02, p. 205-226, 2016.

SAVIANI, D. A filosofia da educação e o problema da inovação em educação. In: GARCIA, W. E. (org). Inovação educacional no Brasil: problemas e perspectivas. São Paulo: Cortez, p. 15-29, 1989.

SEGURA, D. ¿Es posible cambiar la escuela? Bogotá: EPE, 2000.

SEGURA, D.; MOLINA, A.; PEDREROS, R. I.; ARCOS, F. O.; VELASCO, A.; HERNÁNDEZ, G.; LEURO, R. Vivencias de conocimiento y cambio cultural. Bogotá: EPE, 2000.

SHAHARABANI, Y. F.; TAL, T. Teachers' practice a decade after an extensive professional development program in science education. Research in Science Education, v. 47, n.05, p. 10311053, 2017.

STAKE, R. E. Pesquisa qualitativa. Estudando como as coisas funcionam. Porto Alegre: Penso, 2011.

TARDIF, M. Saberes docentes e formação profissional. Petrópolis, RJ: Vozes, 2005.

TRIVIÑOS, A. N. S. Introdução à pesquisa em ciências sociais. São Paulo: Atlas, 1987.

YIN, R. K. Estudo de caso: planejamento e métodos. 3.ed. Porto Alegre: Bookman, 2005.

ZEICHNER, K. M. A formação reflexiva de professores, ideias e práticas. Lisboa: EDUCA, 1993.

\section{NOTAS}

1 "As heranças e repercussões das atividades inovadoras no Ensino de Ciências anos depois de sua implementação". Apoio CNPQ e CAPES.

${ }^{2}$ http://www.roboticaescolar.com/

Submetido em 03/05/2017

Aprovado em 15/01/2018

\section{Contato:}

PUCRS - Escola de Ciências

Prédio $12 \mathrm{~A}-2^{\circ}$ andar.

Av. Ipiranga, 6681

CEP 90.619-900 - Porto alegre, RS - Brasil 


\section{APÊNDICE}

\section{Questionário orientador das entrevistas}

- ¿Cómo fue tu formación?

- ¿Lo que fue más significativo en términos de innovación educativa para ti?

- ¿Qué vivencias positivas de tu formación han influenciado tu práctica hasta los días de hoy?

- ¿Cómo te acercaste a este proceso de innovación? ¿Por qué?

- ¿En qué medida la interacción con tus compañeros de este contexto (innovador) han influenciado o ha influenciado en tus prácticas?

- ¿Y en qué medida crees que contribuye con la mejora de la práctica docente en tu escuela?

- ¿Con quienes ha aprendido o te inspiras a ser un maestro innovador?

- ¿Qué cosas piensas que hoy te quedó en cuanto a tu vivencia con la innovación como maestro?

- ¿Qué cosas positivas has aprendido por haber tenido contacto con la innovación?

- ¿Cuenta como seria para ti una clase innovadora?

- ¿ ¿Se esta es una práctica antigua) Con qué frecuencia la hiciste? ¿(Se esta es una práctica actual) Cómo fue el proceso de evolución para que llegaste a esta clase innovadora?

- ¿Hay algún aspecto de tu práctica ha cambiado de forma permanente? 